\title{
Performance interpretations of musical works
}

Stephen Davies 
In this paper I discuss the factors that go into the interpretation of musical works in performance. My comments are restricted to works specified by standard musical notations and intended for live performance on more or less orthodox musical instruments, and I assume that the performer sincerely intends to play the composer's work rather than, for example, using it as the launching pad for an improvised fantasia. I also suppose that the performer is not the composer and the composer is not available to be consulted.

\section{First, find your work}

To perform and thereby interpret the composer's work, the musician must first locate it, so to speak. Composers communicate their works via sets of instructions addressed to performers. To find the work, one must understand the work-identifying instructions. Doing so requires a considerable amount of knowledge and experience.

To begin, one must know what is unmentioned because it is assumed by the composer as knowledge shared in common with the musicians who are to perform his work. The composer does not (usually) include among the work's specifications instructions about how the instruments are to be built and played. When he indicates something for the violinist to do, he takes for granted that her instrument is appropriately constructed, that it is tuned in the standard fashion, and that she is familiar with and suitably skilled in the performance practice associated with the instrument. That way he can indicate 'Achieve this on a violin' and trust to the performer to know how to execute the instruction. It is only if something non-standard is required in the method of playing, scordatura tunings, mutes, playing with the wood of the bow, that an explicit instruction is needed.

If the music is old, it may not be easy to know what in performance is necessary, tolerable, idiomatic, sophisticated, subtle, coarse but possible, idiosyncratic yet acceptable, standard but mundane, and so on. In extreme cases, we might not know what instruments are to be used or be sure how they are to be played.

In the Western classical tradition, we have a fairly secure knowledge of the performance practice that goes with church and court music of the past four hundred or more years, which is not to deny that there is controversy over many of the details. Even so, complacency would be misplaced. Recordings make us aware how much performance norms (and musical tastes) have altered over 
only the past one hundred years, yet these changes were gradual and largely unremarked by the musicians who perpetuated them. The player is at risk, then, of mistaking current performance practices for accurate representations of the traditions in which the pieces she plays found their homes. She is also in danger of confusing modern equivalents of musical instruments for their predecessors - the clarinet for the basset horn, the Böhm clarinet for the one for which Weber wrote, the pianoforte for the fortepiano, the modern cello for the ancestor that lacked a sound bar, high bridge, endpin, metal strings, sustaining bow, and so forth.

Someone might ask: why should we feel obliged to interpret the work according to outmoded performance practices and on antique forms of instruments? I agree that this question deserves to be taken seriously. But it is one thing to ask sophisticated questions about our interpretative options once we have located the work we are trying to perform and quite another to misidentify that work out of ignorance. It is the latter I am warning against here. The player might decide later that she is justified in departing from the performance practice or instrumentation in which her target work had its genesis, but first she must be sure to find the work she represents herself as giving.

As well as taking for granted the performance practice of his time, the composer also adopts the notational conventions of the day when he records his work-determinative instructions. The score does not usually spell out the vocabulary of signs and the grammar it employs, because it is addressed to musicians who are supposed to be already literate in the notation. The musician has to know notational rules, such as that an accidental applies to all notes of the given pitch in a measure until otherwise cancelled, or that a dot above or below a note indicates that it is to be played staccato. She also needs to know how the performance practice affects the reading of the notation, so that, for instance, some rhythms are to be double-dotted, the melody is to be decorated when it is repeated, and a cadenza is to be interpolated where a caesura is written.

As just indicated, not everything that is notated is to be read literally. Neither is every notational indication work determinative. Scores can contain suggestions or recommendations, for example, regarding fingerings, pedaling, or cadenzas that the performance practice treats as falling within the performer's prerogative. Sometimes scores specify alternatives (e.g., ossia) or indicate note types rather than the tokens that will be played (e.g., figured bass). 
We have a fairly secure knowledge of the notational practices of the West of the past four hundred or more years, which is not to deny that there is controversy over many of the details. Nevertheless, musicians are at risk of mistaking current notational practices for accurate representations of the traditions in which the original score was created. Pierre Monteux, who (in 1949) wanted to give an absolutely authentic performance of the fifth Brandenburg concerto, apparently remonstrated with the continuo player, Putnam Aldrich, 'What are those chords you're playing? Bach wrote no chords here! ... If Bach wanted chords he would have written chords. This is to be an authentic performance. We shall play only what Bach wrote!' (Troeger 2003, p. 218).

The musician also needs an accurate copy of the composer's notation or, if she works from an editor's modern performance version in which there has been a 'translation' (and probably also an expansion of detail) into current notation, a clear account of what was indicated by the composer and what added or amended by the editor. What is crucial is not that a single Urtext exists, but that relevant differences between various sources or versions are shown as such, along with a footnoting of their sources, reliability, plausibility, and so on.

Suppose all these initial conditions are met. As a result, the musician has located the composer's work and identified what is required in delivering it faithfully. Already the first acts of interpretation have been completed; namely, those involved in interpreting (reading) the score in the light of appropriate notational conventions and relevant performance practices. What comes next?

\section{Whose interpretation is to be given?}

A first question asks who is to do the interpreting. In a string quartet, the group might share in the task of generating the interpretation, and hopefully they coordinate their efforts so that the interpretation produced is internally consistent. More often, one person takes overall responsibility. Where there is a conductor, she has the job of shaping the performance's interpretation (provided there is the usual time for rehearsal and explanation). But conductors mainly control pace, balance, expressive highlights, and dynamics. Important though these are, they leave many subtleties of attack, phrasing, and the rest for the interpretation of the individual musicians (or section leaders).

For the sake of simplicity, assume the work is for a single play- 
er, who then will also be its interpreter. She might continue to ask whose interpretation is to be used, if her goal is to emulate some great player of the past. Will she ape Brendel or Rubinstein, copy Du Pré or Rostropovitch? But again to avoid irrelevant complications, let it be the case that she intends to offer her own interpretation.

\section{Authenticity and interpretation}

A crucial choice for this stage is one about the degree of authenticity that will be pursued in the performance. I am reluctant to call this an interpretative decision, having previously written that authenticity is an ontological requirement, not an interpretative option (Davies 2001, p. 207). This principle is entailed by the performer's commitment to playing the composer's work. ${ }^{1}$ To play the work, she must, at the minimum, follow sufficient of the composer's work-determinative instructions to make the work recognizable in her performance. Deliberately and systematically to disregard the majority of those instructions is to fail to perform the work in question, not to interpret it.

Also, it is well to bear in mind that faithfully following all of the composer's public, work-determinative instructions leaves open the possibility of many different interpretations, including ones offering contrasting, even opposed, visions, of the piece. Not all authentic performances are good ones, or provide a convincing account of the work, but even among those that are very good there can be great variety and disagreement. This is because the work-determinative instructions underdetermine much of what goes into any actual performance, including the conception of its overall organization. Even where the tradition allows the composer to be as explicit and detailed in specifying his work as is Mahler, for example, considerable interpretative freedom remains to the performer.

Nevertheless, works can survive in performances that accidentally or deliberately mistreat them. And there can be good reasons for aiming at a degree of authenticity that falls short of what is ideally possible, simply, it can be too difficult, or inconvenient, or aesthetically unattractive, given the circumstances of

1 That commitment was assumed in this discussion as an initial premise. If it does not obtain, the story will be different. But whatever new story is appropriate, it could not be one about the performance of the composer's piece as such. performance.

Only prissy puritans could hold that inauthenticity in musical performance is always egregious. It is disappointing, therefore, that so many musicians spuriously claim authenticity for their performances, and thereby distort what is meant by that useful 
and important notion. They say their performances are authentic because through them they express their heartfelt feelings, or because the composer would have wanted his work done as they do it if only he could have lived to the present, or because they seek out the spirit of the music rather than mechanically following the letter of the score. It would be better, more honest anyway, were they to admit that they have chosen to ignore some of the composer's work-determinative indications, or to make changes in what would usually be work-determinative features in pieces of the kind in question. If we would admit to performing the Prague version of 1787 as against the Vienna one of 1788, why not also allow, if appropriate, that we are giving the slightly remodeled version of 2006 ?

Any performance in which the work remains recognizable could be said to meet the minimum standard for its authentic performance. Because musical works can be recognized in performances in which they are seriously abused, a competent musician who targeted only the minimum would have to deliberately play wrongly many notes she could easily play correctly. Competent musicians, to be accepted as such, must aim higher than the minimum, then. But there is a considerable gap between the minimum and the ideal, and settling for something less than the ideal typically will take the performer far past the minimum. The performer can (and often does) choose to aim lower than the ideal in pursuing authenticity in her performance. And her choices in this regard may turn out to be relevant to the interpretation she offers. For instance, if she chooses to play on the pianoforte a work clearly indicated as for the harpsichord, she will not be able to exploit the interpretative possibilities offered by stops, octave couplings, and multiple keyboards, but she may be able to give the piece a weightier and perhaps therefore a more noble character than would be possible on most harpsichords.

\section{What is interpretation through performance?}

How is a performance interpretation to be characterized? I suggest the following: the performance interpretation of a work, $W$, is the overall expressive and structural vision of $W$ that emerges from $W^{\prime}$ s complete performance. ${ }^{2}$ A given interpretation can be repeated in different performances, including ones by different performers. (So, interpretations are performance types that can have multiple tokens.) And a given performer can offer distinct interpretations of the same work on different occasions.
2 Here I differ from Levinson. (1996, p. 63), who requires in his definition of performance interpretations that they have been considered, by which I take him to mean that the performer who gives the interpretation must have thought about it in advance. 
I claim that a vision of the work emerges from every performance, and hence that every performance embodies an interpretation. Some of these interpretations will be inchoate and silly, however. In other words, as I use it, 'to interpret' is not a success-entailing verb. (In this it is unlike, 'to marry', to take one example.) Also, the vision that emerges is not always projected or even intended by the performer; performance interpretations are not necessarily intended by the people who make them, as I now explain.

Performance necessarily is intentional, but not always to the highest level. In other words, work performance requires the low-level intention to follow some set of work-determinative instructions, but need not depend on the high-level intention to play a given work by a given composer, because the high-level intention can be defeated though a performance takes place. This is what happens when musicians intending to play a trumpet voluntary by Purcell end up performing a piece by Jeremiah Clarke. ${ }^{3}$ Interpretation also is intentional at the low but not necessarily the high level. Interpretational choices are inescapably involved in the most basic performance decisions regarding what and how to play. To play the notes at all, the performer must settle issues of attack, decay, dynamics, vibrato, phrasing, balance, melodic nuance, intonation, harmonic texture, timbre, rhythmic inflection, etcetera, all at a level of subtlety that goes beyond what is determinatively instructed, with the result that interpretation penetrates to the deepest, most elemental level of the performance. But on the other hand, the performer might make these decisions in real time, without prior consideration or concern for the total effect. She might play in the moment, leaving the overall vision to emerge as it will. If she does so, the interpretation that is generated derives from her intentional acts but is not intended by her as such. When that happens, she cannot take credit for the overall expressive and structural vision of the work present in the complete performance, and, at the same time, she may leave herself open to criticism concerning the performance's interpretative failings, given that musicians ought to plan for and interest themselves in the interpretations that result from their performances.

For the sake of this discussion, suppose that the player does calculate and consider the accumulative effect of her local deci-

3 For further discussion of the nature of and conditions on performance, see Thom 1993, Godlovitch 1998, and Davies 2001, ch. 4 . sions on the view presented of the work through its complete performance, as well as focusing on what she will do in the moment. The interpretation projected in her performance will be 
intended and owned by her in the fullest sense. How she will shape her interpretation now will depend on how she conceives the raison d'être of performance interpretations. Several models are worth considering.

\section{Models of interpretation}

According to the first, performance is equivalent to quotation, and the interpretation should aim to communicate the composer's 'utterance' by repeating it with his inflection, intention, and feeling. The player subjugates herself and directs her interpretation to voicing the work as its composer would do. With utterances as complicated and multi-layered as musical works are, it remains likely that many different interpretations, some placing the emphasis here, others there, will be consistent with interpreting the work after this fashion. After all, when composers conduct or play their own pieces on different occasions, they frequently vary the interpretation. The quotation model need not lead to interpretational univocity. Nevertheless, this approach is more selfeffacing and restrictive than is required.

One way the performer could inject more of herself into her interpretation without abandoning the quotation model is by affirming, not merely repeating, the composer's utterance as she conceives it to be. If a person agrees with and asserts what she takes from another as she quotes it, she can make those sentiments expressive of her own thoughts and feelings, not merely a neutral report of theirs. She says 'To thine own self be true' and means it. Performers who feel a close affinity with the character, mood, or attitude of a musical piece probably can personalize their interpretations in the way just described. They appropriate for themselves the significance of what they quote and thereby express themselves (Mark 1981, Davies 2004a).

A third model accords yet more autonomy and freedom to the performer by comparing interpretation with translation. (Note that those who orally translate languages are called interpreters.) Translation is bound to be more creative than quotation, because it can succeed only by adapting what it communicates. So, comparing performance interpretations to translations seems like an improvement, because planned performance interpretations undeniably involve a high degree of skill, judgment, and creativity. Counting against the usefulness of this comparison, however, is the fact that translation involves adapting the original utterance to a different medium or language, whereas the composer and 
4 I assume that performances are made for audiences, whether actual or imagined, and in this differ from rehearsals, practice, exercises, doodling, and so on. Not all musical playings are performances. (And not all performances are of works, of course, though this discussion was restricted at the outset to those that are.) I also suppose that only a tiny minority of listeners can generate virtual performances in their minds' ears simply by reading the work's score.

5 Other musical works are completely encoded as electronically stored files and are for decoding or playback, not performance. performer work in the same medium, even if the composer does so at a more abstract level.

The models of what is involved in work interpretation that have been considered so far have a literary flavor. The initial attractiveness of these models lies in their capturing two central ideas: that the performer mediates between the composer and his audience and that the performer can deliver the composer's work only by interpreting it. These basic intuitions seem right. No decent account of the sort of interpretation being discussed here can forget that it is the composer's work that is interpreted, and that it is only through the performer's interpretation that the work is delivered to its audience. ${ }^{4}$ Nevertheless, while these models could inform and account for some types of musical interpretations, they are not perfectly apt. One difficulty is that of knowing how to parse the metaphor of musical works as composers' 'utterances' standing in need of quotation or translation. And while the model of performance interpretation as quotation underplays the creativity brought by the musician to the act of interpretation, that of interpretation as translation seems to invoke a kind of creativity that does not easily correspond with what the musician does.

Here is a new suggestion. It construes performances on the model of ... well, performances!

Many musical works (and plays) are created for performance. ${ }^{5}$ Among other things, this means that they are issued via instructions about what is to be done or achieved. As described earlier, these work specifications, even when conjoined with the notational conventions and performance practices they take for granted, significantly underdetermine the concrete detail of any actual performance. Though performers undertake the job of instancing the work, they must go beyond the work's boundaries to do this. 'To be or not to be' is integral to Hamlet, but Shakespeare leaves to the actor decisions about the specific inflection, pitch, phrasing, and stress to be used. The words cannot be spoken without being uttered in some specific manner, but it is the words only, not the further qualities displayed whenever the words are spoken, that belong to the play. The melody notated on the opening pages of Beethoven's score for his sixth symphony must be shaped and articulated in every actual sounding of the work with a detail that goes far beyond what is notationally specified (or could be specified in the kind of notation used). In consequence, its performances display many qualities that are not part of the work as such. Because the work can be em- 
bodied or instanced only in the performances that are of it, its presentations always and inevitably have a richness that it does not itself possess. Unlike the work, they are saturated with the sensuous opulence that marks everything that can be immediately perceived via the unaided senses. In its turn, the performance depends crucially for its identity on the work it is of. An attempted work performance fails as a performance unless it presents a work. To say such works are created for performance is to indicate the symbiotic character of the relation between the work and its performances.

It is the performer who brings the work to life. She does this not by delivering it along with some extraneous filigree that comes as a bonus, but by producing a surface that is available to perception and within or through which the work can be apprehended. In other words, she speaks or acts the play or sounds the music. Composers and playwrights know they are licensing the performers to exercise their creative talents by going beyond what has been specified as work determinative. Their works could not be concretely instanced otherwise. Audiences are similarly aware of the importance of the performer's contribution. Indeed, we sometimes recognize individual performances as 'works of art' in their own right. We acknowledge as much when we call the best performers artists and distinguish them from others, such as those who print novels or who screen movies. These latter make artworks available via mechanical processes, but are not performers of the works they transmit.

Interpretation lies at the very heart of performance. Interpretation penetrates every aspect of the generation of a concrete instance of the work. It constructs the ground of the performance, the figure of the work, and the fashion in which the figure emerges against the ground. ${ }^{6}$ Interpretation is not something added after the delivery of the work has been secured. The work is bodied forth through acts of interpretation that infuse it with flesh and breath, blood and muscle. The performer's low- and high-level interpretative decisions generate the electricity needed both to galvanizes the work into life and to energize the ecosystem that sustains its being.

There is no instance of the work without a performance and no performance without an interpretation. Interpretation (and hence performance) is creative because it must go beyond what the composer supplies in order to bring the work alive for the performance's duration. We value (some) musical works and their creators, but we have no less respect and affection for (some)
6 Whether the listener is more interested in the figure, the ground, or the symbiotic relation between the two can vary. Some works are very thin and the audience is liable to attend more to the detail of the performance. Or again, it may be that the work is already very familiar, so the focus falls on what is unusual about its interpretation. 
performance interpretations and for the musicians who exercise inventive, inspired talent in making them.

\section{Wider contextual factors}

So far I have concentrated on the relation of the interpretation to the work it is of. In particular, I have described its purpose as the presentation of an overall vision of the work's structure and expressive character. Though interpretations must be work focused, factors outside the work can be highly relevant to its interpretation on any given occasion.

Among the most obvious of such considerations is the skill of the performer. A musician may be competent to play a work to a standard that results in its (perhaps even faultless) performance, yet not be capable of bringing off all possible ways of playing it. Her technique might be deficient, or it could be limitations in her talent, imagination, experience, nerve, or personality that constrain what she can achieve with the given work. Obviously, she would do well to recognize her boundaries and to pursue only those interpretations she has the ability to realize successfully.

Also to be considered are the proclivities of the particular instrument that is to be played. These might recommend some interpretative options and restrict others. What is interpretationally effective on a particular organ or harpsichord might not work so well on other organs or harpsichords. Even among more or less standardized instruments, such as the violin or pianoforte, there can be significant differences between the instruments produced by different makers, and even between individual instruments. One can be warm sounding where another is brighter and more metallic. This can be relevant to deciding what interpretative selections will promote the preferred overall vision of the work, or will be convincing and desirable at a more local level.

Another issue is the performance's venue. An interpretation that succeeds in the dry acoustic of a salon might be turned to slush in the reverberating interior of a church. The dry acoustic allows the performer to highlight the piece's intricate details, along with the expressive subtleties these permit, whereas the church musician interpreting the same work may be forced to emphasize its broader contours and overall mood.

In addition, whether the performance takes place as part of an examination, a competition, or a recital tour can affect the style of interpretation that is appropriate. A musician whose aim is to demonstrate that she meets some level of technical efficiency 
should highlight her handling of difficult passages. A competitor, as well as doing this, is likely to aim at an interpretation that is powerful and distinctive. A less exaggerated (which is not to say a less interesting or engaging) mode of interpretation is suitable for a public concert, especially if the musician is to play the same piece frequently over a short period.

As well, the agenda of a given performance is set by its audience. If the musician is playing only for herself, she can afford to be introspective or eccentric. If she is playing for a large audience in a hall, she needs to project her account of the work. If the audience is comprised of school children, a straightforward, unsubtle interpretation would be apt, whereas a more exotic, risky, or extreme interpretation might be better appreciated by an audience of experienced listeners who are already familiar with the piece. If the work is new, however, a conservative approach to its interpretation is wanted.

Live concerts and the recording studio lend themselves to different stances as regards interpretation (Davies 2001, ch. 7). Intimate, reflective, fastidious, and polished interpretations are better on recordings. Because recordings can be repeated and are to be lived with, they do not readily tolerate bizarre or hypercharged interpretations. By contrast, styles of interpretation that grab the audience's attention and buoy them along succeed well in the live concert. Meanwhile rough edges, risky maneuvers, and blemishes need not disfigure the live interpretation as they would the recorded one.

A further consideration concerns the work's place in the concert's program and the other pieces with which it is surrounded. The first piece should energize the audience while the remainder should progressively build the intensity of the listeners' involvement and reaction. One would expect a more over-the-top account of Beethoven's Leonore No. 3 overture if it ended the concert, than if it opened it. And if nineteenth-century warhorses flank Bartók's Divertimento, it might stand out more effectively and provide a desirable contrast if its twentieth-century dissonances and rhythms are accented. By contrast, its warmth, charm, and melodic fluidity deserve attention if the remainder of the program consists of works by Webern and Boulez.

\section{Performance interpretations and descriptive interpretations}

The musician interprets the work in performance through her manner of playing it. If she plans the interpretation, she might use trial and error, with final decisions based on gut reactions about what comes off or feels right and what does not. She de- 
signs her interpretation on the basis of intuitions and feelings, without bothering to articulate the reasons behind them. And if it is not planned, the interpretation that emerges from the performance is not intended as such. These facts indicate that there is no reason to believe the performer always will be able to give a verbal account of the overall vision of the work presented in her performance.

The same is true of the performer's low-level interpretative acts. Though these must be intended, it does not follow that they must be intended under a description of what they involve. If the playing of musical instruments becomes automatic, then the player aims directly at the output without concerning herself with the mechanics by which she achieves it (Davies 2004b). Indeed, she might not be able to make the detail of her technique conscious, even if she tries. For instance, she might be able to impart to the melody a wistful nature without being sure what distinguishes this mode of playing from that involved in a "straight" reading of the tune. Moreover, she need not be able to characterize the aural effect that is her target as one of wistfulness. She can intend to produce a sound with a distinctive quality yet have no conception of how to provide a verbal account of what that quality is. That is why so much music teaching proceeds by practical demonstration coupled with grunts and hand waving.

In other words, the musician might not be able to offer a descriptive interpretation that matches her performance interpretation or the low-level, local interpretative acts from which her performance interpretation emerges. This is predictable, given that performance presupposes practical rather than propositional knowledge, or know-how rather than knowing that. A performance interpretation shows the work in a certain light, but without describing it. Indeed, different performance interpretations might be equally consistent with and illustrative of a given descriptive interpretation of the work, and different descriptive interpretations might be compatible with and exemplify a single performance interpretation (Levinson 1996).

As was just explained, some performers might be rendered mute by their own playing, but that is far from the norm. Many can provide verbal explanations of the overall visions that guide their performance interpretations. And even if their overarching performance interpretations are not planned or intended as such, performers sometimes are better than others at reflecting on what they have done and putting their achievements into words. Musicians often can supply eloquent descriptive interpretations 
of their efforts, though this involves skills additional to or apart from those required to create a performance interpretation.

This also should not be surprising. Many musical works provide rich and complex possibilities for performance interpretation. Many musicians are able to exploit these to provide compelling and characterful, yet personal and distinctive, readings of the works they play. There is much to think about, both in trying to understand a musical work and to devise a way of playing it that presents it in a plausible and interesting fashion. Though some of this thinking is likely to involve the aural imagination, it is unlikely that successful interpretation only involves mental rehearsal. Discursive thought inevitably plays a part in considering how things are to be structured or expressed, and languages have impressively large vocabularies with which to represent issues and concepts of form, action, and emotion.

As well as talent, practice, and sensitivity, good musicianship requires intelligence. Intelligence takes in a general aptitude for mental flexibility and ordered thought that fosters and networks communication across a range of domains and processes. Intelligent systems contrast with those made up of task-specific, mutually isolated modules. Though it involves many particular skills and aptitudes, music making is encapsulated and insulated from discursive thought, if ever, only among autistic and idiot savant musicians, and their efforts usually are striking for the untrained technical prowess they display, not for the insightfulness or subtlety of their interpretations. Good musicians are good performing interpreters and good performing interpreters frequently can describe what they do and why. Musical performance and verbal description involve different realms of expression, but what is significant in the former is by no means exclusive of what is meaningful in the latter. ${ }^{7}$

\section{WORKS CITED}

Davies, Stephen. 2001. Musical Works and Performances: A Philosophical Exploration. Oxford: Clarendon Press.

Davies, Stephen. 2004a. Once again, this time with feeling, Journal of Aesthetic Education, 38 (2): 1-6.

Davies, Stephen. 2004b. The know-how of musical performance, Philosophy of Music Education Review, 12 (2): 56-61.

Godlovitch, Stan. 1998. Musical Performance: A Philosophical Study. London: Routledge.

Levinson, Jerrold. 1996. Performative versus critical interpretation in music, in The Pleasures of Aesthetics, Ithaca: Cornell University Press, 6o-89.
7 I am grateful to Paul Thom for comments on a draft of this essay. 
Mark, Thomas Carson. 1981. Philosophy of piano playing: Reflections on the concept of performance, Philosophy and Phenomenological Research, 41, 299-324.

Thom, Paul. 1993. For an Audience: A Philosophy of the Performing Arts. Philadelphia: Temple University Press.

Troeger, Richard. 2003. Playing Bach on the Keyboard: A Practical Guide. Pompton Plains, NJ: Amadeus Press. 
